\title{
Teachers in Post-Modern Era: Narratives of Teaching Subjectivity
}

\author{
Juan José Mouriño Mosquera1, Claus Dieter Stobäus', Juan António Huertas ${ }^{3}$ \\ ${ }^{1}$ Postgraduate Programs in Education, Pontifical Chatolic University of Rio Grande do Sul, \\ Porto Alegre-RS, Brazil \\ ${ }^{2}$ Postgraduate Program in Education and in Biomedical Gerontology, Pontifical Chatolic University of Rio \\ Grande do Sul, Porto Alegre-RS, Brazil \\ ${ }^{3}$ Postgraduate Program in Psychology, Universidad Autónoma de Madrid-Spain, Madrid, Spain \\ Email: stobaus@pucrs.br
}

Received 4 May 2015; accepted 15 June 2015; published 19 June 2015

Copyright (C) 2015 by authors and Scientific Research Publishing Inc.

This work is licensed under the Creative Commons Attribution International License (CC BY). http://creativecommons.org/licenses/by/4.0/

(c) (i) Open Access

\section{Abstract}

This qualitative research examines narratives of 15 teachers, from public and private universities in Porto Alegre-Brazil and public university in Madrid-Spain, about training personal and professional interinfluences using depth interviews, expressed in their narratives about personal, professional and cultural experiences, analyzed using discourse analysis. The following categories are the same as in our another previous work: the option for the profession and remain in it at private university was an intentional choice to be teachers, they have prepared themselves for it. At the public university, they have had some intentionality, enjoying the opportunity to replace colleagues, then undergoing a contest to be effective teachers, and the permanence of both groups is given in order to perform a broader social job; Personal influences, both groups have mentioned that their family and professors/friends examples and contacts with colleagues were good influences on their "decision"; Professional influences, clearly denote here the construction of teachers' subjectivity, in both groups appears the role of a mmntor, as being relevant and meaningful, also teachers stress that their students are important for stimulating professional growth and constant updating. The differences appear much more as identity/identification with the private university, in the public it is more as "fight" and a sense of vindication; Existential route, make clear the process, such as personal and professional view, expanding the construction of their existential dynamic and the need for developing a recognition and self-awareness; Cultural influences, which highlight the globalization, means that there are similarities in the conceptions of life and future prospects, on the other hand, each institution, with its philosophy and dynamics, makes it extremely significant to create situations for the cultural vision of the democratic and social processes. The results also show that these teachers are aware of their personal history influences on their work performance, expressed in feelings and very similar values, their academic lives has more similarities than differences, the stories indicate paths of personal and professional formation are very close, and their story had great cultural influence on their personal and professional development as teachers. 
Keywords

Post-Modernity, Narratives, Teacher's Education, Personal/Professional Development

\section{Introduction}

The concern for the development of personality, especially in the stage of adulthood, and the (continuous/lifelong learning) Teacher's Education has led us to further studies of life stories of educators, through demonstrations of their feelings, cognitions and levels of social interaction, expressed in their narratives. Using the data of the post-doctoral studies that Mosquera developed at the Universidad Autónoma de Madrid, with the supervision of Juan António Huertas, amplified with teacher's data at our university in Brazil, we could discuss about the differences and similarities of these teachers' narratives.

\section{Theoretical Approach}

Pérez Gómez (1998: p. 19), referring to the contemporary situation, says that it is noteworthy that, in recent decades, humans live with the feeling of an inevitable internal and external crisis, especially in the setting of modern culture criticism which has legitimized the model role and teaching practice in our schools, and says:

Modernity, the idea of linear and undefined progress, and productivity rationalist, positivist conception. The colonial and ethnocentric tendency to impose the model of truth, goodness and beauty of the West itself as a top model and homogeneous conception of human development, which discriminates and despises the differences of race, gender and culture crumbles before the evidences of human history in the twentieth century, curd disasters and hostilities.

The theme of postmodernity is undoubtedly challenging, deserving the attention of various authors. When contemplating its effects, they call attention about the influences that present themselves in human behavior and development of the identity of those who live in the crisis of urgency and apparent limitations in the future.

Lyotard (1989) says that postmodernity is characterized by the lack of foundation of the great stories that have given meaning and value to Western history.

Giddens (1993, 1997) seems to agree and he says (Giddens, 1993: p. 16) that "the condition of post-modernity is distinguished by a kind of fading grand narrative and globalizing story line whereby it puts us in history as beings who have a past determined and a predictable future".

We can also say that postmodernity dispenses with the great principles, to open up to an episteme of indeterminacy, discontinuity and pluralism. It is also interesting to note some features that seem to proclaim and set postmodernity.

We followed once again by Pérez Gómez (1998: p. 24), when quoting Spiegel, who emphasized that postmodernism:

[...] postmodernism is an essentially hybrid nature in the world, rejecting the possibility of pure categories of any kind. It is a world of mixed marriages: between words and things, power and imagination, material reality and linguistic construction. Pushed to the limit, deconstruction express our sense of nature discontinuous, fragmented and fractured reality, whose condition is represented by uncertain persistent use of quotes marks.

On highlighting that, in postmodernity, there appear nine characteristics: lack of background of rationality; loss of faith in progress; pragmatism as a way of life and thought; disenchantment and indifference; autonomy, diversity and decentralization; critique of ethnocentrism and universality; multiculturalism and "global village" view; resurgence of fundamentalism, localism and rationalism; historicism, the end of story.

Mosquera (1978) investigated about the affectivity and development of the teacher as a (integral) person, not only with the necessity of has good knowledge, but affect and social interrelations. Nóvoa (1992) speaks about the necessity of recognize the importance of know well the development give support on teachers life. Complementing, Huertas $(1997,1999)$ told us all about the development of a positive motivation to teach and learn, who is influenced by intrinsic and extrinsic factors. Jackson (1991) comments that it is the life in (and outside) the 
classroom.

We believe that those who work in Education can't ignore the theme of postmodernity, because, whether they like it or not, influences are, as we have said, on what we are, on where we are and on what we do, and on where we do. Moreover, it is evident that social culture decisively influences the culture of the teachers.

Hargreaves (1996) has pointed out that the changes influence on topics such as personal history, labor problem, problem of time, meaning of culture and future prospects. We understand that many teachers live, consciously or unconsciously, what he calls the "malaise of the modernity".

The teacher is placed at the crossroads with the postmodern paradoxes, such as globalization, the end of certainties, the mobile mosaic of culture and the need for self-assertion, which is before a distressing problem. Therefore, questions like, what we know about the careers of teachers and about their own lives draw a lot of attention nowadays. The form it takes is the culture of the teachers, and Hargreaves (1996), who also studied life histories of teachers, gives us the models of relationships and forms of association that have a decisive influence on the dynamics of teachers and how to configure the act of teaching and its impact on students' learning.

We are interested in the four major forms of culture teachers, which were proposed by the same author, also confirmed by Pérez Gómez (1998), they are: individualism; collaboration; artificial collegiality; and balkanization. On individualism, both authors emphasize that the vast majority of teachers continue to apply their skills by themselves, stranded and on closed doors. This seems to be a tonic, and it is found in all types and categories of Education. On the other hand, the individualism of teachers does not necessarily mean self-sufficiency or autonomy, but often reveals major problems and doubts.

The research reported by Hargreaves (1996) denotes that many teachers in elementary schools work in isolation, although there is an apparent collaboration. Always interested us, and this research is implied on it, that teachers understand how the phenomenon of live individualism and as a consequence, the loneliness they experience when that same individualism denies collaboration and sharing of critical activity, proposed for a more emancipatory teaching.

As for the other two forms, collaboration and artificial collegiality, Pérez Gómez (1998: p. 170) states that:

The collaboration and collegiality among teachers, as part of their professional competence, have acquired quickly the meaning of a new orthodoxy of the processes of change and innovation in school. It believe that collaboration translates the professional development of teachers beyond the limited and local horizons of individualism and isolation, dependence on outside experts, where teachers can learn from each other, to share their experiences, thoughts and fears.

These phenomena have been pretty stressed lately, when we want that teachers are able to not only reflect on their actions, but also are able to learn to share their experiences, values, expectations and interests as and in a group.

These two fundamental elements, collaboration and artificial collegiality, can shed much light on the behavior of teachers, their performances and especially the development of its characteristics as a person and as a professional. Now, it is opportune to state that a new thread is pointed, balkanization, which, according to Hargreaves (1996) is taken as a metaphor from the events in Yugoslavia, which have long been considered as a jewel of the Eastern bloc, in which the cause of the rupture of the block is configured as schisms, linguistic and ethnic conflicts as never seen before.

Another feature is the lasting permanence in the group, i.e., forming what we can express as, in our culture, "feuds", the "churches" with their "ministers and devout". They are redoubt in which a viewing time cannot leave once out can never be a return claim. As a result of lasting permanence, the personal identification develops, as in balkanized cultures people bind especially subcommunities, in which is contained and defined most of his working life.

In the latter category was also included political balkanization, since these subcultures of teachers are not simply sources of identity and meaning, but also promoter of elements on personal and group interests.

Hargreaves (1996) says that in balkanized cultures, in the political sense, there are winners and losers. We would add to these categories of the humiliated the offended (who are "below"), the victors and rulers (who are “above”).

All these elements so far commented lead us to understand that we cannot separate arbitrarily, the cultural and social transformations of those people, and the careers (and backgrounds) lives of the teachers. Therefore, the interplay that occurs between culture and personality development of the teacher seems as utmost importance. 


\section{Methodology}

Our research is qualitative and the objectives are approximate the issue of postmodern narratives of university professors, we analyze and approach these narratives of university teachers of Madrid-Spain and Porto AlegreBrazil.

The Thematic Area is expressed as: Postmodernism and its influence on personal and professional lives of teachers, and the Research Questions are: What narratives narrate the teachers? What professional experiences narrate the teachers? Which tell teachers about their cultural development? What differences and similarities appear in these two distinct cultural realities, Spain and Brazil?

The participants are 15 university teachers, intentionally chosen due to the fact that they have being working at their university for at least five years; they have different professional and personal experiences, also teaching, researching and publishing, they have being working as least 20 hours a week and with recognition and representation at their university, seven of them are from Madrid (Universidad Autónoma de Madrid-UAM) and eight of them are in Porto Alegre (Pontifícia Universidade Católica do Rio Grande do Sul- PUCRS). The selection was also intentional by taking into account those who show a rich life and are particularly concerned with culture and society, just taking into consideration people who have much to tell about all these aspects. The instruments were in-depth interviews, biographical imprint called narratives, which revealed dimensions of their subjectivity and the influence of cultural reality in their experiences and transformations, lasted on average one and a half hours.

Data were collected initially in Spain, between October and November of 1999, in Brazil the data were mainly collected in December of 1999 and late February of 2000.

The group of UAM professors that works on Psychology Faculty and their subject's average age varies between 35 and 59 years old. The age of professors from PUCRS is among 49 and 64 years old, they work at the Education Faculty as their first option in the field of Education. A more general conclusion we have reached is that there is a great connection between the two university "environments", so that we studied some of their teachers. Knowledge and ideas give the academic environments to approach to ideals have been recognized (recognizable) as similar and have very close academic language (despite their linguistic differences).

After having conducted discourse analysis (Ricoeur 1991, 1994, 1995, 1997; Genette, 1996; McEwan \& Egan, 1998; Perroni, 1992), complemented by textual analysis, we highlight the dimensions obtained, report some of the narratives contained in the interviews, first with the UAM teachers, after with the PUCRS teachers, to perform the following approaches.

\section{Teachers from Madrid-Spain}

\subsection{Category-Choice of Profession and Remain in It}

This dimension had several interesting indicatives. For example, teacher 1 tells us that it was " $a$ set of coincidences”, since he was interested in being a Psychology professional, when he had the offer of being a university teacher. Still expresses his desire to be a teacher was also to "stay young”, feeling that could learn continuously in a rich and stimulating environment. Stays now in teaching because it is like the act of teaching, but the administrative and bureaucratic is not always to their liking and preference.

Teacher number 4 declares that was "the accident" that turned him into a teacher, confessed clearly the lack of interest in the beginning of his career, and after established an agreement with the profession, because of the possibility of reading and researching. Once report "I believe it was really random because I had sworn not to teach never, not ever live in a small town". Already on staying in the profession emphasizes that "I believe that now better take lessons until I can have fun with them".

There is an agreement on how people become teachers. Somehow, they were taken to be, and remain in the profession for interest or acceptance of it, or seeing the possibilities in the context become researchers and theorists.

\subsection{Category-Personal Influences}

The teacher number 3 highlights the relevance of their parents, especially the father figure, some anchored in conventionality, which became a rich and meaningful model of identity. Also their maternal model was important to have another dynamic of personality, and therefore, “more feet on the ground". 
The teacher number 5 says that his personal desires highlight a remarkable willingness to see more in the future of the world, traveling, writing, and composing. Says that "all we have is the past, I believe that you can't do is live anchored in the past, since living convicted of the past is bound to be equal to place limits", showing constant concern on the need to overcome the limitations in their life and, at the same time, becoming a more personalized person, with high critical sense.

The teacher number 6 places a strong tendency to have group life, which develops a sense of leadership, turning into " $a$ kind of small leader". Firstly allows the pleasure of working and helping other people, both those who have conditions that, as with the difficulties, which means it has a strong social sense.

Here we note the important influence of parents, a mentor, even cultural environments and situations experienced.

\subsection{Category-Professional Influences}

The teacher number 3 shows professional influence from their experience in various universities to which he was attached, that help to understand the level of quality that is the academic as well as the influence of a natural person, their intellectual mentor now deceased, which enabled improved knowledge, in-depth investigations.

For the teacher number 7 the professional influences were felt from the moment he became student representative of all college students before the rectory, then getting to see inside the university. Narrates their own life history, with a promising carries marked by excellence in academic performance as a student, as a teacher had stimuli and recognition of their form of leadership.

The dimension is inextricably linked to the size personal influences like the idea of independence and personal autonomy, in other narratives is clear the academic staff and senior groups, expressed a desire for continuity, but in a direction of more.

\subsection{Category-Existential Journey}

The teacher number 1 commented that his story was influenced from the choice of profession, his beliefs and attitudes, sizing professionals and, especially, the progress of academic career, marked by two sabbatical years and, even more, accepting the idea of a midlife crisis and the desire to be independent of the institutional requirements and the need of more intellectual depth. We believe it is symbolic when he tells "has interested me, always, be creative, take flight even with little theoretical rigor. [...] I think the vital plane and see that history is a narrative included within another narration, now no post-modernized. In order to trash the great stories, this immediately".

This teacher reveals a strong sense of self, and does not ignore the strong change being carried out of the society and culture. This leads us to realize its concern with what happens in the historical moment in which someone wants to influence not just be influenced.

The teacher number 6 emphasizes that the origin of most of the choices are in his teens, with a concern for Paleontology and approach to the evolution of human beings and their health aspects. On the influence of family and intellectual conditions, he decided to study Psychology and stress his concern about the motivation within and outside of the classroom, like the research, knowledge, and especially for being a teacher in a changing culture and demanding, considering, and indeed it is, people prepared for leadership and production knowledgeservice.

There are diversity of influences, family moments and life experiences related to their life development as intrinsic personal and professional experiences, able to score and even change the course of life.

\subsection{Category-Cultural Influences}

The teacher number 3 reports that had major influences from the end of the adolescence and early young adulthood, being aware of the lived time of transition, which affected in their choices and did become aware of the transformations undergone by the Spanish society in recent years. Narrates that "the option I have now is an option that I interpret as very tough and very tight to what is expected of a person of my age. I think I know it's not fair, but I believe that despite disenchanted, we think the country's political and democratic participation".

For teacher number 4, the cultural and political change does not seem to have affected much, nor have lived in a period dictatorship because it expresses who finished the last year of the time when Franco (Spanish President) 
died, the change is noted with elections, the change in the constitution and reports: "I had changed my life so much more, from my point of view, because he had left to live with my parents to go to a city and live alone and start a career". On the other hand, living outside Madrid, the less noticed decisions that were taken in the Spanish capital, since was "on the edge".

\section{Teachers from Porto Alegre-Brasil}

\subsection{Category-Choice of Profession and Remain in It}

Most participants expressed that the choice of occupation was marked by strong personal interest from an early age, detected in five of the eight respondents. There were influences in the family environment and the type of farming received, while stating that the teaching as profession help in a better understanding of the relationship between humans and especially if you can see your product and growth in others.

Teacher number 5 reports that "playing to teach, I was dolls teacher, which were duly placed in rows, to learn the lessons that I, with a ruler, was giving to them". Showed true passion early on, and by the "Magisterium" (professorship course), in her words, like the stories of life when it tells us that comes from a family in which the cultural environment was like by culture, reading and arts, with influential relatives who were teachers.

Teacher number 8 also expressed what led her to become a teacher could be several reasons, among them a sister teacher, and toys were a teacher. About staying in the profession, she mentioned: "it is a taste, an energy, an emotion is very particular, is a fullness of life, is an exchange of knowledge with students, is a process of building shared that made me stay in the profession". Her talk stands a strong tendency to teach, having a marked influence of the cultural environment, since the time of her development as person, Education had a strong influence and was considered desirable for the promotion and advancement of life, while as personal fulfillment. Remain in the profession and have positive influence from/in the environment in which they work.

\subsection{Category-Personal Influences}

We also found certain ideas in participants of our staff, as recounted when teacher number 1 reports that the family is highly influential because he has always been interested in knowledge, perhaps by appreciation and respect for knowing and, at the same time, the taste and performance in family policy. Another aspect that relates, is the value given to their moral and ethical studies, which make him understand better the social transformation of society and the future, the teacher will be credited as a strong family structure.

For teacher number 4, family influences were of great importance, especially from his parents, with well demarcated and values that served as his models for the development of a free and critical thought. He expresses that he has a strong appreciation for a democratic society, free of authoritarianism, believing strongly in the freedom of thought. In this regard narrates his conception of psychological time, the highlight is: "past, present and future, including course not, we will have more experience of life and we become more ironic and even you're having fun sometimes".

There are reports about the place that the family occupies in the development and construction of subjectivity, confirming that interpersonal relationships help more families profoundly shape the psychological world, pave the way for choices we make (and face) in life.

\subsection{Category-Professional Influences}

The teacher number 2 highlights that the key influence for the profession is the "flowering of truly human being quality to which we give the name of man, but to become a man must humanize himself". With this phrase, he wants to emphasize the deep philosophical sense of the profession, seeing the human subject with a strong influence in the act of continuing to be a teacher.

For teacher number 6, the influences become professionals already since attending "Normal School" (Secondary School), at the time, to say: "I had a practicum experience that was very rewarding, with children from less privileged social class [....]", in the sense of contact with students and have seen how it has influenced the growth of them. It makes clear that the professional influences can be expressed through symbolic rewards when he tells us that "what makes me stay in the profession is when it arrives in the room classroom and see the eyes of the students, adding that there is [...] satisfaction and joy to see the growth of the students and their curiosity".

Note that there is a special and meaningful importance when he mentions that he is able to have contact with students and to observe their growth. 


\subsection{Category-Existential Journey}

The route usually has an existential sense that helps us better understand the narratives of people, emphasizing the temporal meaning, which is embodied in its making, that is, in its performance as a whole.

When, for example, the teacher number 2 highlights that since the intentional choice to be a teacher until the moment of his/her life, there is an important existential thread, literacy teacher as the option for many years. In fact she said she worked it highlights, then attended Social Sciences, then the Postgraduate Education, with his Doctoral Thesis on teachers literacy (closing a sort of circle, circuit) and her major concern is the human relationship is contact with the other, for the objectivity and the development of self-image and self-esteem.

This route already shows us a human dimension, marked by the growth of staff and other persons.

The teacher number 8 draws attention to the development of her route is marked by different time, she highlights as three times, in different moments, as administrative, academic and personal. Highlights the need for good psychological structure to be able to establish interpersonal relationships and be able to be successful, this teacher evidence sensibility with scholarly work, especially teaching and tells that "the time of the teacher in class is the harvest time of fruit, to see things happen, enchantments, with emotion". This tells us that the path of this teacher did not "freeze" in the dimension that has as Administrator, but always remained tied to time of teaching.

\subsection{Category-Cultural Influences}

Cultural influences are, in our opinion, one of the most significant dimensions to understand the development of subjectivity, which causes the work to be understood in a more striking and critical way, since competition in which we have a profession, says Mosquera (1987), is one of the characteristics that mark the most in Adulthood.

The influence of culture is imminent, for example, when the teacher number 3 shows that "political history marked my life in the time of the military regime, but it did not inhibit my task of Christian integrity in defense of ideas, even though my sermons and my classes recorded and subsequently having my scholarship abroad locked for a while [...], the main concerns were to keep alive the Christian faith and to help the poor and needy people".

As for the teacher number 1, the policy environment was tagged in a family situation and helped a lot to understand the value of freedom and sharpen his knowledge and curiosity, by the society in which he lives, especially, to better understand the life moment, the role of institutions and networks of power.

Participants highlighted the need for freedom, both in a personal sense and professionally. In addition, they consider all the democratic space as the most suitable for the highest levels of human and social development.

\section{Discussion}

In a common element, the Spanish teachers and Brazilian teacher reveal (directly/indirectly) that they are living in a period of world space and time of a globalized culture, characteristic of postmodern society.

A second element to highlight is about the option and stay in profession. Spanish teachers showed, preferably, the choice was made for several casualties or interests and studies, more connected to the theoretical and research, and this led them to be and remain as teachers. Brazilian teachers already narrated mostly preference in being an educator from an initial option, which later led also to the theoretical and research field.

On the third place are the personal influences, in which has to be noted that there is a large overlap between the two groups. We can highlight the role of their parents, key figures as well as their intellectual mentors, groups of friends and colleagues, associations and especially their personal manifest desires, most likely the result of cultural influences, specifically the development of their personality, the different stages of their educational and psychological history.

The fourth highlight is the professional influences, both groups were similar, reiterating that the respondents relevant figures of persons, among them his/her mentors, academic history which could accomplish, working groups and colleagues, creating new courses, which takes into account aspects such as their professional responsibilities and their collaboration. Comment on the use of literature and authors updated, research techniques and great democratization of knowledge.

A fifth point to be noted, within the existential journey, marked by globalization, reveals similarities and differences in cultural characteristics experienced by these times in the beginning of the 21st Century, because each of their subjectivities development occurs according to their genetic history and psychosocial development pe- 
culiarities.

In addition, it should be noted by the group from Spain that, being more directly implied in Psychology and related topics, reveals a remarkable concern for the educational area, including conducting scholarly work of great merit in this area. In Brazil, the key concern of the group is the behavior and knowledge in Education, also in Social Sciences and Psychology.

As final point we emphasize that there are cultural influences, noting that they have been living similar situations with respect to political and social systems, which resemble in historical terms. Both groups mention restrictions of social and cultural order, which influenced their everyday life and, more specifically, in their education. The differences are in how in these two countries the persons faced the sociopolitical contingences and revealed their peculiar history.

\section{Conclusions}

This work can be the beginning of a larger social research project already underway that led us to study, in depth, the narratives of university teachers, in a postmodern society. It can also be the beginning of a cross-cultural study, strongly characterized by the psychological and educational aspects.

It is also the result of an experience of transcultural study, which serves as an alert to a better understanding of the subjectivity of teachers that are important teacher trainers, whether in the field of Psychology or Education.

After these considerations, we can also say that the world in which we live now is both: very small and very large at the same time.

\section{References}

Genette, G. (1996). Discurso da narrativa (3rd ed.). Alpiarça: Vega. [Original: (1988). Narrative Discourse Revisited. New York: Cornell University Press].

Giddens, A. (1993). Consecuencias de la modernidad. Madrid: Alianza. [Original: (1991). The Consequences of Modernity. Cambridge: Polity Press ].

Giddens, A. (1997). Modernidade e identidade pessoal. Oeiras: Celta. [Original: (1991). Modernity and Self-Identity: Self and Society in the Late Modern Age. Cambridge: Polity Press].

Hargreaves, A. (1996). Profesorado, cultura y postmodernidad. Madrid: Morata. [Original: (1994). Changing Teachers, Changing Times. London: Cassell].

Huertas, J. A. (1997). Motivación. Querer aprender. Buenos Aires: Aiqué,.

Huertas, J. A. (1999). Cultura del profesor y modos de motivar: a la búsqueda de una gramática de los motivos. Madrid: Universidad Autónoma.

Jackson, Ph. W. (1991). La vida en las aulas. La Coruña/Madrid: Paideia/Morata. [Original: (1990). Life in Classrooms. New York: Teachers College Press].

Lyotard, J. F. (1989). La condición postmoderna. Madrid: Cátedra. [Original: (1984). The Postmodern Condition. Manchester: Manchester University Press].

McEwan, H. , \& Egan, K. (1998). La narrativa en la enseñanza, el aprendizaje y la investigación. Buenos Aires: Amorrortu. [Original: (1995). Narrative in Teaching, Learning, and Research. New York: Teachers College Press].

Nóvoa, A. (Ed.). (1992). Vidas de professores. Porto: Porto Editora.

Pérez Gómez, Á. I. (1998). La cultura escolar en la sociedad neoliberal. Madrid: Morata.

Perroni, M. C. (1992). Desenvolvimento do Discurso Narrativo. São Paulo: Martins Fontes.

Mosquera, J. J. M. (1978). O Professor como Pessoa. Porto Alegre: Sulina.

Mosquera, J. J. M. (1987). Vida Adulta (3rd ed.). Porto Alegre: Sulina.

Ricoeur, P. (1991). O si mesmo como um outro. Campinas: Papirus. [Original: (1990). Soi-même comme un autre. Paris: Le Seuil].

Ricoeur, P. (1994). Tempo e Narrativa. Tomo I. São Paulo: Papirus. [Original: (1983). Temps et récit. Tome I: L'intrigue et le récit historique. Paris: Le Seuil].

Ricoeur, P. (1995). Tempo e Narrativa. Tomo II. São Paulo: Papirus. [Origina: (1984). l Temps et récit. Tome II: La configuration dans le récit de fiction. Paris: Le Seuil].

Ricoeur, P. (1997). Tempo e Narrativa. Tomo III. São Paulo: Papirus. [Original: (1985). Temps et récit. Tome III: Le temps raconté. Paris: Le Seuil]. 